\title{
Anfis İle İlgili Yapılmış Çalışmaların İçerik Analizi İle Değerlendirilmesi: Tr Dizin
}

\author{
Mesut Polatgil $^{1^{*}}$

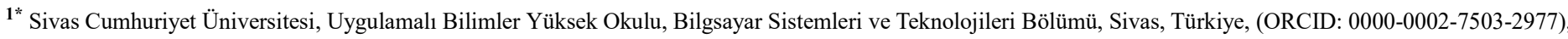 \\ mesutpolatgil@cumhuriyet.edu.tr
}

(Uluslararası Araştırma-Geliştirme ve Tasarım Konferansı - 15-18 Aralık 2021)

(DOI: 10.31590/ejosat.1039699)

ATIF/REFERENCE: Polatgil, M. (2021). Anfis İle İlgili Yapılmış Çalışmaların İçerik Analizi İle Değerlendirilmesi: Tr Dizin. Avrupa Bilim ve Teknoloji Dergisi, (32), 1086-1093.

\section{Öz}

Uyarlamalı ăg tabanlı bulanık çıkarım sistemi (ANFIS), son yıllarda yapay zekâ çalışmaları kapsamında sıklıkla tercih edilen yöntemlerden birisidir. Birçok farklı alanda ve farklı türde verilerde başarılı sonuçlar vermesi ile de gün geçtikçe önem kazanmaktadır. Bu konuda yapılmış çalışmaların analiz edilerek genel bir değerlendirmesinin yapılması bir ihtiyaçtır. Bu araştırmanın amacı, TR Dizin kapsamında yer alan dergilerde yayınlanmış ANFIS ile ilgili yapılmış çalışmalarının analizini gerçekleştirmektir. Tr Dizin kapsamında taranan dergilerde yayınlanmış Anfis ile ilgili 102 çalışma analiz edilmiştir. Analizler Maxqda analiz programı ile gerçekleştirilmiştir. Çalışmalar tarih, veri normalizasyonu, verilerin eğitim test şeklinde bölünmesi, performans değerlendirmesi, karşılaştırılan yöntemler ve bir arada kullanılan yöntemler bakımından analiz edilmiştir. Analiz sonuçları Maxqda programı grafik ve görselleri ile desteklenerek verilmiştir. Çalışma sonucunda son yıllarda Tr Dizin kapsamında, Anfis ile ilgili çalışmaların sayısında artış olduğu fakat çalışmalarda veri normalizasyonu, verinin eğitim ve test için ayrılması ile performans ölçümünde kullanılan metrikler ile ilgili ciddi eksiklikler olduğu tespit edilmiştir. Çalışma sonuçlarının Anfis ile ilgili yapılacak çalışmalarda destekleyici bir rol oynayacağı düşünülmektedir.

\section{Evaluation Of The Studies Related To Anfis With Content Analysis: Tr Index}

\begin{abstract}
Adaptive neuro-fuzzy inference system (ANFIS) is one of the frequently preferred methods within the scope of artificial intelligence studies in recent years. It is gaining importance day by day with its successful results in many different fields and different types of data. It is a need to analyze and evaluate the studies on this subject. The purpose of this research is to analyze the studies on ANFIS published in journals covered by TR Index. 102 studies on Anfis published in journals scanned within the scope of Tr Index were analyzed. Analyzes were carried out with Maxqda analysis program. Studies were analyzed in terms of history, data normalization, division of data into training tests, performance evaluation, compared methods and methods used together. Analysis results are given with the support of Maxqda program graphics and visuals. As a result of the study, it has been determined that the number of studies related to Anfis has increased in recent years within the scope of $\mathrm{Tr}$ Index, but there are serious deficiencies in data normalization, separation of data for training and testing, and metrics used in performance measurement. It is thought that the results of the study will play a supportive role in the studies to be carried out on Anfis.
\end{abstract}

Keywords: Machine Learning, Artificial Intelligence, Tr Index, Maxqda, Anfis.

*Sorumlu Yazar: mesutpolatgil@cumhuriyet.edu.tr 


\section{Giriş}

Yaşadığımız dünyada önemli olaylar olmuş ve bazıları bir dönüm noktası şeklinde düşünülmüştür. Bu dönüm noktalarından birisi de yapay zekânın ortaya çıkışı ve hayatımızda önemli bir role sahip olmasıdır. Yapay zekâ ile ilgili birçok tanım bulunmaktadır. $\mathrm{Bu}$ tanımların ortak özelliği, insan zekâsının makineler aracılığı ile taklit edilmesi üzerine odaklanmasıdır (Pirim, 2006). Bulanık mantık, yapay sinir ağları, optimizasyon teknikleri gibi yöntemler literatürde önerilmiş ve farklı alanlarda farklı türde problemlerin çözümünde başarı ile kullanılmıştır (Calvo-Flores vd., 2006; Niaki ve Hoseinzade, 2013; Yang vd., 2014; Ziasabounchi ve Askerzade, 2014).

Yapay zekâ tekniklerinden en çok bilinenlerden birisi olan bulanık mantık Zadeh, 1965, tarafından önerilmiştir. Klasik mantık düşünme biçiminde bir eleman bir kümeye ya aittir ya da ait değildir. Fakat bulanık mantık bir elemanın birden fazla kümeye ait olmasını göz önünde bulundurur. Eğer-ise şeklinde kurallar ile oluşturulur. Yapay sinir ağları ise insan beyninin çalışma biçimini esas alan başka bir yöntemdir. Giriş ve çıkış değerlerinden oluşan bir veri setini kullanarak nöronlar arasındaki ağırlıkları güncelleme esasına göre çalışır. Kaç katman olacağı ve bu katmanlardaki nöronun sayılarının ne olacağının belirli olmaması ve nöronlar arasındaki ağırlıkların bir anlamının olmaması yapay sinir ağlarının bir dezavantajıdır.

Bulanık mantık ve yapay sinir ağlarının bir araya gelmesi ile hibrit bir yapay zekâ tekniği olan Anfis ortaya çıkmıştır. İki önemli yapay zekâ tekniğini bir araya getirmesi ile güçlü bir yapıya sahip olan Anfis araştırmacıların da dikkatini çekmiş ve son yıllarda yapılan çalışmalarda artışa neden olmuştur. Bu artışın yansıması Türkiye'nin en geniş veri tabanı olan Tr Dizi'nde de görülmeye başlanmıştır. TR Dizin, 2013 yılı sonuna kadar Ulusal Veri Tabanları-UVT adıyla yürütülmüştür. Uluslararası standartlarla araştırmacıların bilimsel içeriğe elektronik ortamda ulaşması amaçlanmıştır. 2000 yılından beri elektronik olarak araştırmacılara hizmet vermektedir. Fen ve Sosyal Bilimler alanında hizmet veren dergiler $\operatorname{Tr}$ Dizin kapsamında taranmaktadır ve bu dizin kapsamında ki dergiler konu uzmanları akademisyenlerden oluşan ekipler tarafindan incelenmekte ve dizine kabulü yapılmaktadır.
Tr Dizin kapsamında 2021 y1lına kadar Anfis ile ilgili 102 çalışmanın gerçekleştirildiği görülmektedir. $\mathrm{Bu}$ çalışmaların farklı alanlarda ve farklı veri türlerinde yapılması da ayrıca dikkat çekicidir. Yani Anfis sadece Fen Bilimleri ya da Mühendislik Bilimlerinde değil Sosyal Bilimlerde de kullanılabilen bir yöntemdir. $\mathrm{Bu}$ yöntemin bir Fen Bilimleri çalışması ile Sosyal Bilimler çalışmasında kullanılması araştırmalarda farklı bakış açılarının ortaya çıkmasına neden olmaktadır. Bir alanda etkin olarak kullanılan bir yaklaşım Anfis ile ilgili yeni yapılan çalışmalarda kullanılmamakta ya da göz ardı edilebilmektedir. Örneğin birçok çalışma geleneksel olarak veri setini eğitim-test olarak test seferde bölme üzerine odaklanırken yeni yaklaşımlar bu yöntemden ziyade çapraz geçerlilik yöntemlerini kullanmaya yönelmektedir. $\mathrm{Bu}$ nedenden dolayı, Anfis ile ilgili yapılan çalışmaların genel bir değerlendirmesinin yapılarak çalışmaların ortak ve farklı yönlerinin ortaya konması ve ileride yapılacak çalışmalara rehber olması önemli bir ihtiyaçtır. Bu çalışma bu ihtiyacı gidermek amacı ile Tr Dizin kapsamındaki Anfis ile ilgili yapılmış 102 adet çalışmanın içerik analizi ile incelenmesi yoluyla gerçekleştirilmiştir. Çalışmanın aynı zamanda Maxqda içerik analizi yazılımı ile gerçekleştirilerek yazılımın özellikle grafiksel özelliklerinin kullanılarak gerçekleştirilmesi de özgün tarafidir.

\subsection{Kaynak Araştırması}

Ülkemizde elektronik ortamda araştırmacılara kolay bir şekilde bilimsel araştırmalara ulaşma imkânı veren Tr Dizin, 2000 yılından itibaren hizmet vermektedir. $\mathrm{Bu}$ bağlamda bazı araştırmalar $\operatorname{Tr}$ Dizin kapsamında yapılımış çalışmaları inceleyerek genel bir bakış açısı sağlamışlardır (Deveci ve Koç, 2020; Özer ve Demirbatır, 2021).

Fakat böyle bir bakış açısının Anfis ile ilgili çalışmalarda olmadığı tespit edilmiştir. Bu çalışma literatürdeki bu ihtiyacı karşılamak amacı ile gerçekleştirilmiştir.

\subsection{Anfis}

ANFIS Jang (1993) tarafından geliştirilen bir yapay zekâ yöntemidir. Hem bulanık mantık hem de yapay sinir ağlarını içeren bir yöntemdir. Giriş ve çıkış değerlerinden oluşan bir verietinde Anfis eğer-ve şeklindeki kuralları otomatik olarak oluşturabilmektedir. Anfis sisteminin işleyişi Şekil 1'de gösterilmiştir (Roger Jang ve Sun, 1993).

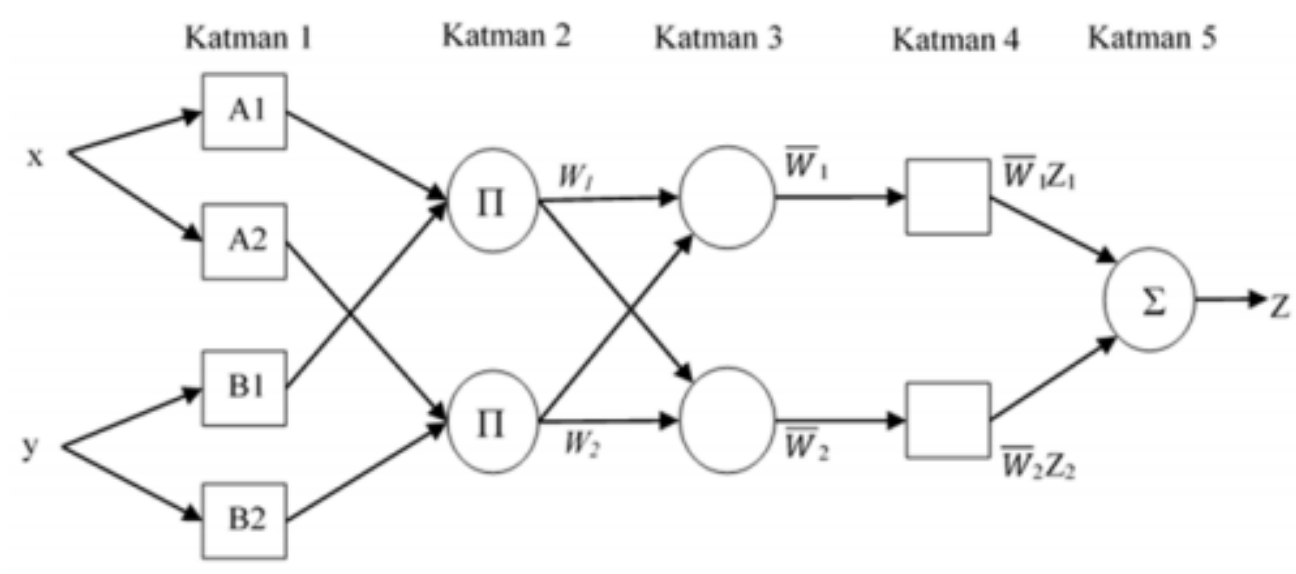

Şekil 1. Anfis yapısı (Anfis structure) 


\section{Materyal ve Metot}

Bu çalışmada Tr Dizin kapamında Anfis ile ilgili yayınlanmış çalışmaların içerik analizi gerçekleştirilmiştir. Anfis ile ilgili 102 adet çalışmanın bulunduğu tespit edilerek çalışmaların tam metni elde edilmiştir (https://app.trdizin.gov.tr/). Elde edilen tam metinler Maxqda analiz programına aktarılarak kodlamaları gerçekleştirilmiştir.
Tr Dizi'de taranan araştırmaların tarihleri bakımından yapılan incelemesi sonuçları Şekil 2'de verilmiştir. Çalışmaların özellikle 2018 ve 2019 yıllarında önemli artış gösterdiği tespit edilmiştir.

Tr Dizi'de taranan araştırmaların tarihleri bakımından yapılan incelemesi sonuçları Şekil 2'de verilmiştir. Çalışmaların özellikle 2018 ve 2019 yıllarında önemli artış gösterdiği tespit edilmiştir.

\section{Bulgular}

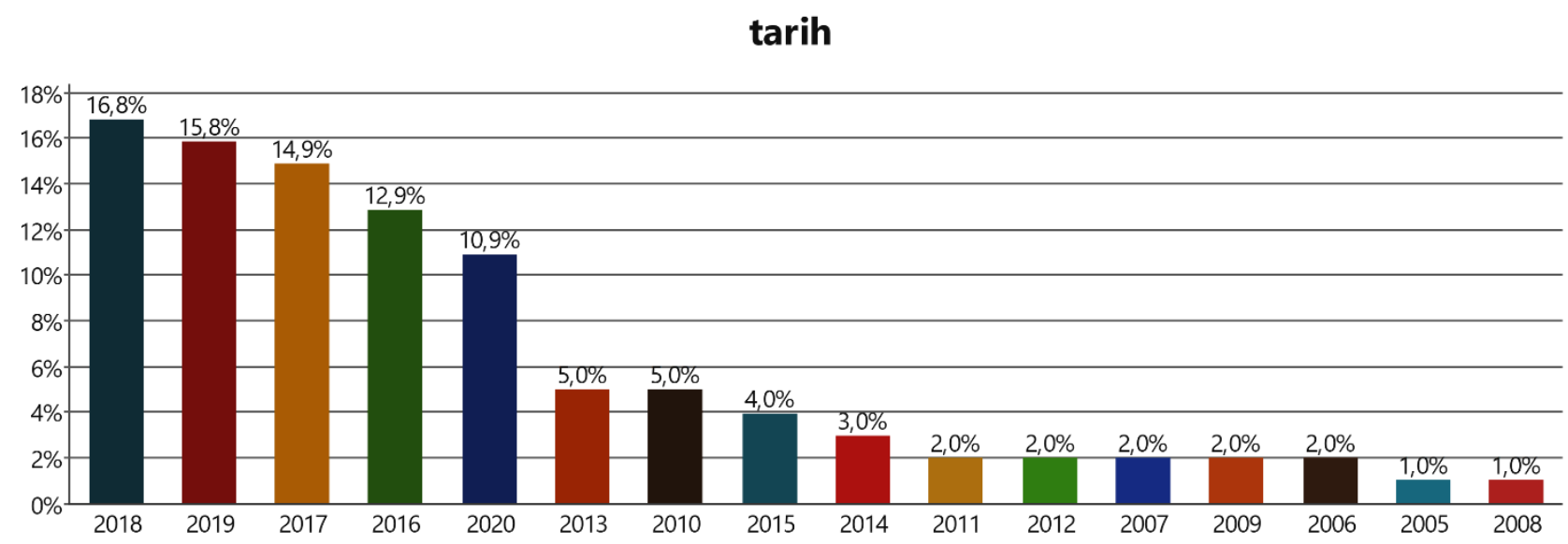

Şekil 2. Çalışmaların tarihine göre analizi (Analysis of studies by date)

Araştırmalarda kullanılan veri bölme yöntemleri incelemesi sonuçları Şekil 3'de verilmiştir. Çalışmalarda yaklaşık \% 92 oranla eğitim-test şeklinde verileerin bölünmesi oldukça dikkat çekicidir.

\section{veri_bolme}

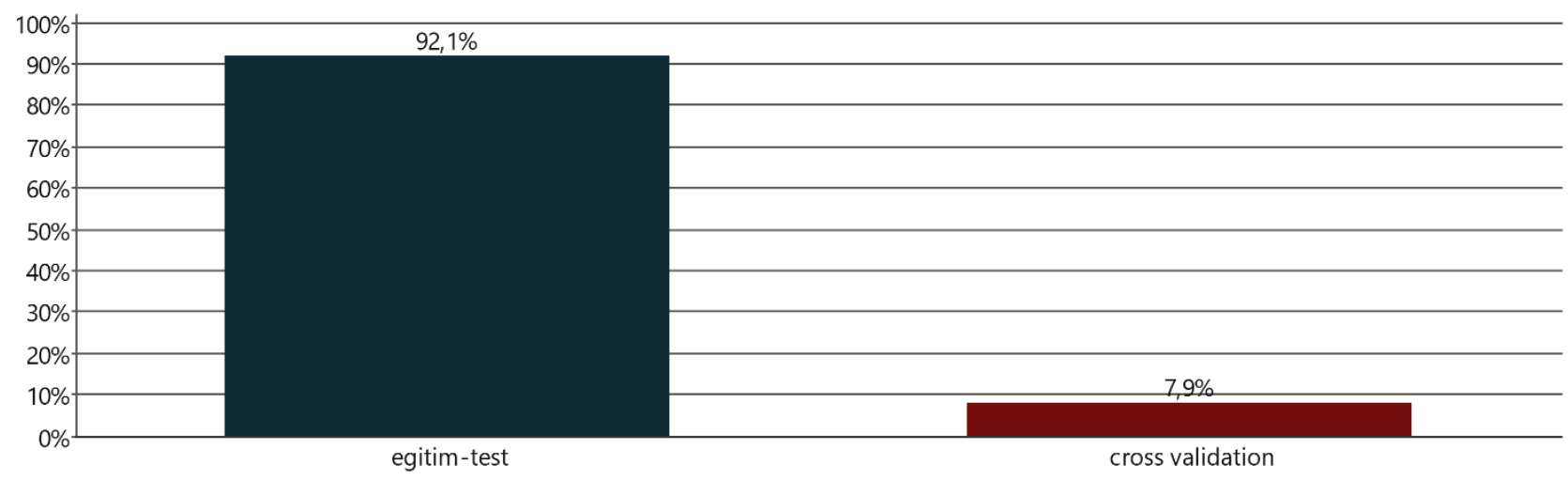

Şekil 3. Çalışmaların veri bölme yöntemine göre analizi (Analysis of studies according to data division method)

Araştırmalarda kullanılan veri normalizasyonu yöntemleri incelemesi sonuçları Şekil 4'de verilmiştir. Çalışmalarda yaklaşık \% 79 oranla kullanılan veri üzerinde bir normalizasyon yapılıp yapılmadığı bilgisinin olmadığı tespit edilmiştir. 
veri_norm

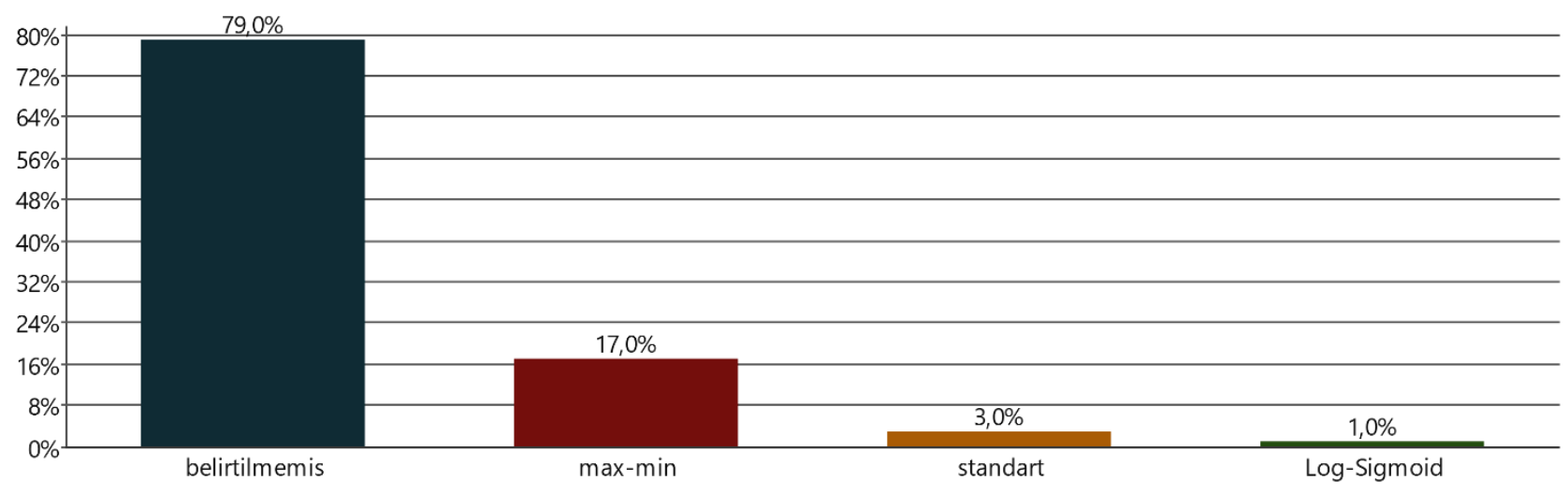

Şekil 4. Çalışmaların veri normalizasyon yöntemine göre analizi (Analysis of studies according to data normalization method)

Araştırmaların yapıldı̆̆ sonuçları Şekil 5'de verilmiştir. Çalışmalarda yaklaşık \% 40 oranla çevre ile ilgili konular üzerine araştırmalar yapıldı̆̆ 1 görülmüştür.

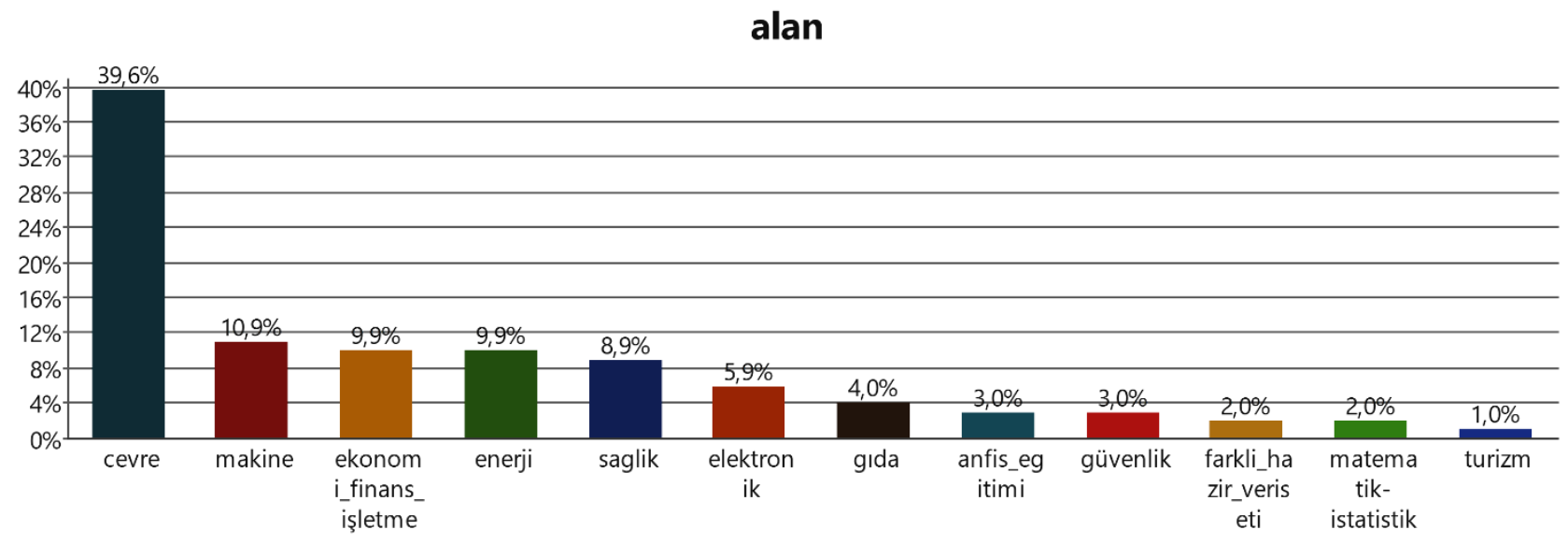

Şekil 5. Çalışmaların yapıldı̆̆ alana göre analizi (Analysis according to the field of study)

Araştırmalarda kullanılan performans yöntemlerinin incelenmesi sonuçları Tablo 1'de verilmiştir. Çalışmalarda farklı performans ölçüm yöntemlerinin tercih edildiği görülmüştür.

Tablo 1. Çalışmalarda kullanılan performans yöntemlerine göre analizi (Analysis according to the performance methods used in the studies)

\begin{tabular}{|l|l|l|}
\hline & Bölümler & Yüzde \\
\hline SİIIFLANDIRMA & 13 & 12,87 \\
\hline GRAFIK & 12 & 11,88 \\
\hline MSE & 12 & 11,88 \\
\hline RMSE & 10 & 9,90 \\
\hline R2-MAE-MSE & 6 & 5,94 \\
\hline R2_RMSE_MAPE & 5 & 4,95 \\
\hline R2 & 5 & 4,95 \\
\hline R2-RMSE & 4 & 3,96 \\
\hline R2-MSE & 4 & 3,96 \\
\hline RMSE-MSE & 3 & 2,97 \\
\hline
\end{tabular}

\begin{tabular}{|l|l|l|}
\hline MAPE & 3 & 2,97 \\
\hline MAE-RAE-RMSE-RRSE & 2 & 1,98 \\
\hline R2-MAE & 2 & 1,98 \\
\hline MSE-RMSE-MAE-MAPE & 2 & 1,98 \\
\hline R2-MPE & 2 & 1,98 \\
\hline R2-MAPE & 2 & 1,98 \\
\hline RMSE-MAPE & 2 & 1,98 \\
\hline MAE-MAPE & 1 & 0,99 \\
\hline RMSE-MAE & 1 & 0,99 \\
\hline R2-MSE-MAE-MAPE & 1 & 0,99 \\
\hline RMSE-MAE-MAPE & 1 & 0,99 \\
\hline Taylor-MAE-NSC & 1 & 0,99 \\
\hline R2-RMSE-MAE-MBE & 1 & 0,99 \\
\hline R2-MSE-RMSE-MAPE-MAD & 1 & 0,99 \\
\hline R2-MAE-MAPE-CME & 1 & 0,99 \\
\hline RMSE-MAE-NSC & 1 & 0,99 \\
\hline MSE-MAE-ARE & 1 & 0,99 \\
\hline
\end{tabular}




\begin{tabular}{|l|l|l|}
\hline R2-RMSE-MAE & 1 & 0,99 \\
\hline R2-RMSE-MAE-MAPE & 1 & 0,99 \\
\hline
\end{tabular}

Anfis ile ilgili yapılan çalışmalarda Anfis yöntemi ile birlikte kullanılan diğer yöntemler bakımından incelenmesi sonuçları Tablo 2'de verilmiştir. Çalışmalarda farklı yöntemlerin dail edilme oranın düşük olduğu tespit edilmiştir.

Tablo 2. Çalışmalarda bir arada kullanılan yöntemlerine göre analizi (Analysis according to the methods used together in the studies)

\begin{tabular}{|l|l|l|}
\hline & Bölümler & $\begin{array}{l}\text { Yüzd } \\
\text { e }\end{array}$ \\
\hline belirtilmemis & 82 & 82,00 \\
\hline GA & 2 & 2,00 \\
\hline $\begin{array}{l}\text { DISCRETE WAVELET } \\
\text { TRANSFORM (DWT) }\end{array}$ & 1 & 1,00 \\
\hline FORWARD SELECTION & 1 & 1,00 \\
\hline KORELASYON & 1 & 1,00 \\
\hline ABC & 1 & 1,00 \\
\hline FCM-KMEANS & 1 & 1,00 \\
\hline $\begin{array}{l}\text { PCA-LDA-İSOMAP-LLE-AE-LLC- } \\
\text { SMAP }\end{array}$ & 1 & 1,00 \\
\hline LOGITT-PROBIT & 1 & 1,00 \\
\hline PSO & 1 & 1,00 \\
\hline WAVELET & 1 & 1,00 \\
\hline FCM & 1 & 1,00 \\
\hline DİFERANSIYEL GELİŞIM & 1 & 1,00 \\
\hline KMEANS & 1 & 1,00 \\
\hline MOTH-FLAME OPTIMİZTION & 1 & 1,00 \\
\hline KMEANS-GA & 1 & 1,00 \\
\hline PCA & 1 & 1,00 \\
\hline $\begin{array}{l}\text { SHORT TERM FOURIER } \\
\text { TRANSFORM }\end{array}$ & 1 & 1,00 \\
\hline & & \\
\hline
\end{tabular}

Anfis ile ilgili yapılan çalışmalarda Anfis yönteminin elde etiği sonuçların hangi yöntemlerle karşılaştırıldığı bakımından incelenmesi sonuçları Tablo 3'de verilmiştir. Çalışmalarda en çok yapay sinir ağları yönteminin karşılaştırılma amaçlı tercih edildiği tespit edilmiştir.

Tablo 3. Anfis sonuçlarının karşılaştırıldı ̆̆ yöntemlere göre analizi (Analysis of the amphitheater results according to the methods compared)

\begin{tabular}{|l|l|l|}
\hline & Bölümler & $\begin{array}{l}\text { Yüz } \\
\mathbf{d e}\end{array}$ \\
\hline BELIRTILMEMIS & 52 & $\begin{array}{l}52,0 \\
0\end{array}$ \\
\hline YSA & 19 & $\begin{array}{l}19,0 \\
0\end{array}$ \\
\hline PİD & 6 & 6,00 \\
\hline SVM-YSA & 4 & 4,00 \\
\hline YSA-MLR & 3 & 3,00 \\
\hline YSA-GEP & 2 & 2,00 \\
\hline REGRESYON & 2 & 2,00 \\
\hline ESDP-MM & 1 & 1,00 \\
\hline KMEANS & 1 & 1,00 \\
\hline GARCH & 1 & 1,00 \\
\hline RANDOMFOREST & 1 & 1,00 \\
\hline ARMA & 1 & 1,00 \\
\hline SVR-YSA & 1 & 1,00 \\
\hline ANGSTRÖM-PRESCOTT & 1 & 1,00 \\
\hline $\begin{array}{l}\text { CFOREST_CUBIST_ELASTİCNET_B } \\
\text { MARS_XGBOOST }\end{array}$ & 1 & 1,00 \\
\hline BULANIK_MANTIK & 1 & 1,00 \\
\hline $\begin{array}{l}\text { TRANSFER } \\
\text { MATRIX METHOD (TMM) }\end{array}$ & 1 & 1,00 \\
\hline SVM-RF-LR-DT & 1 & \\
\hline MM & & 1,00 \\
\hline
\end{tabular}

\section{Sonuç ve Tartışma}

$\mathrm{Bu}$ çalışmanın amacı Anfis ile ilgili yapılmış Tr Dizin kapsamındaki çalışmaların içerik analizini gerçekleştirmektir. Analiz sonuçlarına göre Anfis ile ilgili Tr Dizin kapsamında 102 çalışma olduğu tespit edilmiştir. $\mathrm{Bu}$ çalışmalar tarihleri bakımından incelendiğinde 76 tanesinin yani \% 75' inin son 5 yılda gerçekleştiği tespit edilmiştir. Son yıllarda yapay zekâ ve makine öğrenmesi ile ilgili yapılan çalışmaların artması ve farklı yöntemlere olan yönelimler bu sonucun ortaya çıkmasında önemli rol oynamış olabilir.

Çalışmaların yapıldığı alan bakımından incelendiğinde ise yaklaşık \% 40 ile çevre ile ilgili konular üzerine araştırmalar yapıldığı tespit edilmiştir. Özellikle sağlık, finans ve enerji ile ilgili konularda çalışmaların yaklaşık \% 10 civarında olduğu görülmüştür. Bu sonuçlar son yıllarda küresel ısınma, depremler ve firtınalar gibi afetlerin yaygınlaşması ile çevreye yönelik konulara ağırlık verilmiş olabileceği düşündürmektedir. Fakat sağlık ve enerji gibi hayati derecede önemli konular üzerine Anfis sisteminin başarısının test edildiği çalışmaların yapılması gerektiği tespit edilmiştir.

Anfis ile ilgili çalışmalarda en belirgin özelliklerden birisi çalışmaların yaklaşık \% 13'ü ile sınıflandırma türünde tahmin çalışmaları olduğunun görülmesidir. Çok az çalışmada sınıflandırma yapılması dikkat çekicidir. Çalışmaların genellikle regresyon türü tahmin verilerinde kullanılması Anfis'in bu tür verilerde başarılı performans göstermesinden dolayı olabilir. 
Dolayısı ile sınıflandırma türünde çalışmalarda Anfis kullanılması ve Anfis'in sınıflandırma verilerinde de ne kadar başarılı olduğunun gösterilmesi bu alanda bir ihtiyaç olarak görünmektedir.

Çalışmalarda hibrit yöntemlerin tercih edildiği çalışmalar incelendiğinde genellikle kümeleme analizi tekniklerinden kmeans ve fuzzy c-means kümeleme teknikleri ile optimizasyon tekniklerinden olan genetik algoritmaların Anfis yöntemi ile birlikte kullanıldığı tespit edilmiştir (Calp, 2019; Haznedar vd., 2016; Küçükerdem vd., 2019; Yılmaz vd., 2020). Bazı çalışmalarda ise diğer çalışmalarda kullanılmamış yöntemlerin kullanıldı ̆̆ tespit edilmiştir. Temel bileşenler analizi (Gökler ve Boran, 2020), logit-probit yöntemi (Söyler ve Kızılkaya, 2018), dalgacık dönüşüm uygulanması (Taylan, 2018), korelasyon analizi (Efendigil ve Emin Eminler, 2017), ileri seçim yönteminin kullanılması (Moazami vd., 2016) bu çalışmalardan bazılarıdır. Bazı çalışmaların ise Anfis sisteminin eğitilmesine odaklanarak farklı algoritmaların eğitilme işleminde kullanılması üzerinde odaklandıkları tespit edilmiştir (Canayaz, 2019; Ceylan ve Bulkan, 2018; Dokur vd., 2019; Karaboğa ve Kaya, 2017).

$\mathrm{Bu}$ sonuçlardan çalışmalarda Anfis'in başka yöntemlerle birlikte kullanımının yaygınlaştığı fakat çok farklı yöntemler kullanıldığı ve bunların kullanım sebepleri ile sonuçların etkinliğinin gösterilmesi noktasında çalışmalara ihtiyaç olduğu tespit edilmiştir.

Anfis yönteminin başarısının karşılaştırılması durumu incelendiğinde ise çalışmalarda genellikle yapay sinir ağları ile karşılaştırma yönteminin tercih edildiği dikkat çekmektedir. Çok az çalışmada Anfis sisteminin diğer makine öğrenmesi yöntemlerinden birden fazlası ile karşılaştırıldığ 1 tespit edilmiştir (Ac1 vd., 2018; Gholami vd., 2020). Fakat çalışmaların yaklaşık yüzde 52'sinde Anfis sonuçlarının başka yöntemlerle karşılaştırılmadığı görülmektedir. Bu sonuçlar Anfis ile ilgili yapılan çalışmalarda sonuçların başka makine öğrenmesi yöntemleri ile karşılaştırılarak sonuçların raporlanması gerekliliğini ortaya koymaktadır.

Verilerin normalize edilmesi makine öğrenmesi ve yapay zekâ çalışmalarında önemli konulardan birisidir. Değişkenlerin değer aralıkları bakımından birbirinden farklı olması sistemin performansını etkileyebilen bir özelliktir. Anfis ile ilgili çalışmalar incelendiğinde verilerin normalize edildiği ve raporlandığı yirmi bir çalışma olduğu tespit edilmiştir. Bunlardan sadece üç tanesi standart normalizasyon tekniğini kullanırken (Canayaz, 2019; Sönmez vd., 2018; Y1lmaz vd., 2020), sadece bir çalışmada ise Log-Sigmoid normalizasyon kullanıldığ görülmüştür (Şengöz ve Özdemir, 2016). Çalışmaların yüzde 79'unda ise normalizasyon ile ilgili bilgi olmadığ 1 görülmektedir. $\mathrm{Bu}$ sonuçlar çalışmalarda normalizasyon işlemi yapılıp yapılmadığının ve yapıldı ise hangi yöntemin uygulandığının rapor edilmesi gerekliliğini ortaya koymaktadır.

Anfis çalışanlarının yaklaşık \% 92'sinde verilerin eğitim-test şeklinde bölündüğü görülmektedir. Sadece 8 çalışmada k kat çapraz geçerlilik yöntemine başvurulmuştur (Acı ve Yılmaz, 2017; Altaher ve Barukab, 2017; Görgel vd., 2013; Haznedar vd., 2016; Haznedar ve Kalınlı, 2016; Kaynak vd., 2018; Moazami vd., 2016; Polatgil, 2020). Veri setinin bir kısmının eğitim ve bir kısmının test olarak bölünmesi modelin doğruluğu için yaygın kullanılan bir yöntem olmakla birlikte önemli bir dezavantaja sahiptir. Veri setinin farklı şekillerde bölünmesi modelin değerlendirilmesinde de farklı sonuçlar vermesine neden olur. Fakat k kat çapraz geçerlilik yönteminde bu sorun ortadan e-ISSN: 2148-2683 kaldırılabilmektedir. Bu yüzden modellerin başarı düzeylerinin test edilmesinde bu yöntemin daha fazla tercih edilmesi gerekliliği ortaya çıkmıştır.

Anfis yönteminin performans değerlendirmesinin yapıldığ çalışmalarda ise farklı performans ölçüm değerlerinin kullanıldığg görülmüştür. Çalışmaların yaklaşık \% 12'sinde MSE, en çok performans değerlendirme ölçümü tercih yöntemi olmuştur. Çalışmaların yaklaşık \% 10'unda ise RMSE yöntemi tercih edilmiştir. Bazı çalışmalarda ortalama yüzde hata kullanılırken (Acar ve Saplıoğlu, 2020), bazı çalışmalarda (Kayabaşi ve Akdağli, 2016) ise mutlak ortalama yüzde hata kullanılması dikkat çekicidir. Çalışmaların \% 5'inde sadece R2 değeri ile performans ölçümü yapması ise oldukça ilgi çekici olmuştur (Erten vd., 2020; Gökler ve Boran, 2020; Göktepe vd., 2005; Saltan ve Alaefary, 2018; Ünal vd., 2018). Çünkü R2 değeri iki değişken arasındaki ilişkiyi veren istatistik ibir ölçüttür ve bu ölçütün tek başına Anfis sisteminin başarısında kullanılması tam bir başarı gösterimi olarak kabul edilmesi güçtür. Bazı araştırmalarda ise diğer araştırmalarda neredeyse hiç kullanılmamış performans değerlendirme ölçütü kullanılmıştır. Örneğin (Gholami vd., 2020), çalışmalarında performans ölçümü için Taylor diyagramını kullanmışlardır. Bazı çalışmalarda ise performans ölçüm yöntemleri kullanılmayarak sadece grafiksel bir sunum yapılması ise oldukça dikkat çekicidir (Atlihan vd., 2017; Caner vd., 2009; Çoban ve Bilgiç, 2019; Dalkilic ve Apaydin, 2009; Güngör ve Özdemir, 2018; Havangi vd., 2012; Keçecioğlu ve Kılıç, 2019; Miloudi vd., 2007; Oğuz ve Güney, 2010; Ortatepe ve Parlaktuna, 2017; Şit vd., 2016; Toylan ve Hüner, 2017). Bu sonuçlar araştırmalarda performasn ölçüm yöntmelerinin kullanılmasında uygun olan yöntemlerin seçilerek birden fazla yöntemin bir arada kullanılması gerekliliğini ortaya koymaktadir.

\section{Kaynakça}

Acar, R., ve Saplıoğlu, K. (2020). Akarsulardaki Sediment Taşınımının Yapay Sinir Ağları Ve Anfıs Yöntemleri Kullanılarak Tespiti. Ömer Halisdemir Üniversitesi Mühendislik Bilimleri Dergisi, 9(1), 437-450. https://doi.org/10.28948/ngumuh.681208

Acı, Ç., Acı, M., ve Avcı, M. (2018). Performance Comparıson Of Anfis, Ann, Svr, Cart And Mlr Techniques For Geometry Optımization Of Carbon Nanotubes Using Castep. Turkish Journal of Engineering, 2(3), 119-124. https://doi.org/10.31127/tuje.408976

Acı, Ç., ve Yılmaz, C. A. (2017). Maddi Hasarlı Trafik Kazaları İçin Sinirsel-Bulanık A ğ Tabanlı Bir Kusur Tespit Modeli. In Fırat Üniv. Müh. Bil. Dergisi Science and Eng. J of Fırat Univ (Vol. 29, Issue https://dergipark.org.tr/tr/pub/fumbd/339605

Altaher, A., ve Barukab, O. (2017). Android malware classification based on ANFIS with fuzzy c-means clustering using significant application permissions. Turkish Journal of Electrical Engineering and Computer Science, 25(3), 2232 2242. https://doi.org/10.3906/elk-1602-107

Atlihan, M., Yalcin, B. C., ve Erkan, K. (2017). Force and torque parameter estimation for a 4-pole hybrid electromagnet by ANFIS hybrid learning algorithm. Turkish Journal of 
Electrical Engineering and Computer Sciences, 25(5), 36843698. https://doi.org/10.3906/elk-1605-364

Calp, M. H. (2019). A Hybrid ANFIS-GA Approach for Estimation of Regional Rainfall Amount. Gazi University Journal Of Science, 32(1).

Calvo-Flores, M. D., Galindo, E. G., Jiménez, M. C. P., ve Pérez, O. (2006). Predicting students' marks from Moodle logs using neural network models. Proceedings of the IV International Conference on Multimedia and Information and Communication Technologies in Education (M-ICTEE2006), $1,586-590$.

Canayaz, M. (2019). Training Anfis System with Moth-Flame Optimization Algorithm. International Journal of Intelligent Systems and Applications in Engineering, 7(3), 133-144. https://doi.org/10.18201/ijisae.2019355375

Caner, M., Akarslan, E., ve Tarihi, G. (2009). Mermer Kesme İşleminde Spesifik Enerji Faktörünün ANFIS ve YSA Yöntemleri ile Tahmini. Pamukkale Üniversitesi Mühendislik Bilimleri Dergisi, 15(2), 221-226.

Ceylan, Z., ve Bulkan, S. (2018). Estimation of Turkey's Transportation Energy Demand by Hybrid ANFISPSO. Afyon Kocatepe University Journal of Sciences and Engineering, 18(2), 740-750. https://doi.org/10.5578/fmbd.67331

Çoban, S., ve Bilgiç, H. H. (2019). Different Autopilot Systems Design For a Small Fixed Wing Unmanned Aerial Vehicle. European Journal of Science and Technology, 17, 682-691. https://doi.org/10.31590/ejosat.639309

Dalkilic, T. E., ve Apaydin, A. (2009). A fuzzy adaptive network approach to parameter estimation in cases where independent variables come from an exponential distribution. Journal of Computational and Applied Mathematics, 233(1), 36-45. https://doi.org/10.1016/j.cam.2008.07.057

Deveci, M., ve Koç, E. S. (2020). Öğrenme Güçlüğü Konusunda Yayınlanmış Makalelerin Karşılaştırmalı Olarak İncelenmesi, WOS ve TR Dizin Örneği. İnsan ve Toplum Bilimleri Araştırmaları Dergisi, 9(5), 4088-4120. https://doi.org/10.15869/itobiad.774509

Dokur, E., Yüzgeç, U., ve Kurban, M. (2019). Diferansiyel Gelişim Algoritma Tabanlı Uyarlamalı Sinirsel Bulanık Çıkarım Sistemi ile Kısa Dönem Rüzgâr Hızı Kestirimi. Bitlis Eren Üniversitesi Fen Bilimleri Dergisi, 8(3), 1057-1068. https://doi.org/10.17798/bitlisfen.534246

Efendigil, T., ve Emin Eminler, Ö. (2017). Havacılık Sektöründe Talep Tahminin Önemi: Yolcu Talebi Üzerine Bir Tahmin Modeli. Journal of Yaşar University, 12(48), 14-30. https://doi.org/10.19168/jyu.31243

Erten, K. M., Terzi, S., Akbulut, H., ve Erişkin, E. (2020). ANFIS ve Bulanık Mantık Yöntemlerinin Köpük Bitümün Genleşme Oranı ve Yarılanma Süresi Parametreleri Tahmininde Kullanılabilirliğinin Araştırılması. Düzce Üniversitesi Bilim ve Teknoloji Dergisi, 8(4), 2388-2399. https://doi.org/10.29130/dubited.686047

Gholami, H., Mohamadifar, A., Sorooshian, A., ve Jansen, J. D. (2020). Machine-learning algorithms for predicting land susceptibility to dust emissions: The case of the Jazmurian
Basin, Iran. Atmospheric Pollution Research, 11(8), 13031315. https://doi.org/10.1016/j.apr.2020.05.009

Gökler, S. H., ve Boran, S. (2020). PCA Esaslı Hibrit ANFISTaguchi Yöntemi ile Kan Bankası için Talep Tahmini. Bilișim Teknolojileri Dergisi, 13(3), 225-233. https://doi.org/10.17671/gazibtd.580530

Göktepe, A. B., Ağar, E., ve Lav, A. H. (2005). Comparison of multilayer perceptron and adaptive neuro-fuzzy system on backcalculating the mechanical properties of flexible pavements. ARI The Bulletin of the Istanbul Technical University, 54(3), 65-77.

Görgel, P., Sertbas, A., ve Turusbekova, A. (2013). Classification of breast masses using anfis-based fuzzy algorithms: A comparative study. Istanbul University - Journal of Electrical and Electronics Engineering, 13(1), 1605-1611.

Güngör, O., ve Özdemir, A. (2018). Güneş Panellerinde IC Ve ANFIS Tabanlı MPPT Algoritmalarının Karşılaştırmalı Performans Analizi. Erciyes Üniversitesi Fen Bilimleri Enstitüsü Dergisi, 34(2), 50-59.

Havangi, R., Nekoui, M. A., ve Teshnehlab, M. (2012). An improved FastSLAM framework using soft computing. Turkish Journal of Electrical Engineering and Computer Sciences, 20(1), 25-46. https://doi.org/10.3906/elk-1004-504

Haznedar, B., Arslan, M. T., ve Kalınlı, A. (2016). Karaciğer mikrodizi kanser verisinin sınıflandırılması için genetik algoritma kullanarak ANFIS ' in eğitilmesi Training ANFIS structure using genetic algorithm for liver cancer classification based on microarray gene expression data. SAÜ Fen Bilimleri Enstitüsü Dergisi, 21(1), 54-62. https://doi.org/10.16984/saufenbilder.41925

Haznedar, B., ve Kalınlı, A. (2016). Trombofili Hastalığı İle Genetik Bozukluklar Arasındaki İlişskinin Adaptif A ̆ Tabanlı Bulanık Mantık Çıkarım Sistemi (Anfis) İle Tespit Edilmesi. SAÜ Fen Bilimleri Enstitüsü Dergisi, 20(1), 13. https://doi.org/10.16984/saufenbilder.40786

Karaboğa, D., ve Kaya, E. (2017). Training ANFIS by using the artificial bee colony algorithm. Turkish Journal of Electrical Engineering and Computer Sciences, 25(3), 1669-1679. https://doi.org/10.3906/elk-1601-240

Kayabaşi, A., ve Akdağli, A. (2016). Oyuk yüklü kompakt mikroşerit antenlerin rezonans frekansinin hesaplanmasinda ysa ve bmsdua yöntemlerinin kullanimi. Journal of the Faculty of Engineering and Architecture of Gazi University, 31(1), 105-117. https://doi.org/10.17341/gummfd.71495

Kaynak, S., Kaynak, B., ve Evirgen, H. (2018). Student Consultancy Service: Prediction of Course Grades in Course Selection Phases Using Artificial Intelligence Techniques. Journal of Computer and Education Research, 6(12), 142162. https://doi.org/10.18009/jcer.421123

Keçecioğlu, Ö. F., ve Kılıç, E. (2019). Tristör Kontrollü Reaktörün Sinirsel Bulanık Denetim Esaslı Reaktif Güç Kontrolü. Gazi Üniversitesi Fen Bilimleri Dergisi Part C: Tasarım ve Teknoloji, 7(2), 399-410. https://doi.org/10.29109/gujsc.530219

Küçükerdem, T. S., Kilit, M., ve Saplioglu, K. (2019). Determination of the number of clusters used in fuzzy inference systems by means of K-means and modeling of dam 
volume: Kestel dam example. Pamukkale University Journal of Engineering Sciences, 25(8), 962-967. https://doi.org/10.5505/pajes.2019.99223

Miloudi, A., Al-Radadi, E. A., ve Draou, A. D. (2007). A variable gain PI controller used for speed control of a direct torque neuro fuzzy controlled induction machine drive. Turkish Journal of Electrical Engineering and Computer Sciences, 15(1), 37-49.

Moazami, S., Noori, R., Amiri, B. J., Yeganeh, B., Partani, S., ve Safavi, S. (2016). Reliable prediction of carbon monoxide using developed support vector machine. Atmospheric Pollution Research, 7(3), 412-418. https://doi.org/10.1016/j.apr.2015.10.022

Niaki, S. T. A., ve Hoseinzade, S. (2013). Forecasting SveP 500 index using artificial neural networks and design of experiments. Journal of Industrial Engineering International, 9(1). https://doi.org/10.1186/2251-712X-9-1

Oğuz, Y., ve Güney, I. (2010). Adaptive neuro-fuzzy inference system to improve the power quality of variable-speed wind power generation system. Turkish Journal of Electrical Engineering and Computer Sciences, 18(4), 625-645.

Ortatepe, Z., ve Parlaktuna, O. (2017). Two Dof Robot Control With Fuzzy Based Neural Networks. ANADOLU UNIVERSITY JOURNAL OF SCIENCE AND TECHNOLOGY A - Applied Sciences and Engineering, 18(4), 819-830. https://doi.org/10.18038/aubtda.340002

Özer, Z., ve Demirbatır, R. E. (2021). Müzik Eğitimi İle İlgili Tr Dizin Veri Tabanında Yayınlanan Araştırmaların Eğilimlerinin Belirlenmesi. Abant İzzet Baysal Üniversitesi Eğitim Fakültesi Dergisi, 21(1), 282-304. https://doi.org/10.17240/aibuefd.2021.21.60703-796990

Polatgil, M. (2020). Anfis ve Bulanık K Ortalamalar İle Kalp Hastalığının Tespit edilmesi. Bilişim Teknolojileri Dergisi, 13(4), 443-449. https://doi.org/10.17671/gazibtd.731678

Roger Jang, J. S., ve Sun, C. T. (1993). Functional Equivalence Between Radial Basis Function Networks and Fuzzy Inference Systems. IEEE Transactions on Neural Networks, 4(1), 156-159. https://doi.org/10.1109/72.182710

Saltan, M., ve Alaefary, F. (2018). ANFIS YÖNTEMININ ESNEK YOL ÜSTYAPILARININ YAPISAL ANALIZINDE KULLANILABİLİRLİĞİ. Mühendislik Bilimleri ve Tasarım Dergisi, 6(3), 32-41. https://doi.org/10.21923/jesd.313427

Şengöz, N., ve Özdemir, G. (2016). Sınıflandırma Problemlerinin Karşılaştırılmasında ANFIS ve Basamak Korelasyon Sinir Ağının Kullanımı. Süleyman Demirel Üniversitesi Fen $\begin{array}{llll}\text { Bilimleri Enstitüsü } 125 . & \text { Dergisi, 21(1), }\end{array}$ https://doi.org/10.19113/sdufbed.15545

Şit, S., Özçalık, H. R., Kılıç, E., Doğmuş, O., ve Altun, M. (2016). Asenkron Motorların Online Adaptif Sinirsel-Bulanık Denetim (ANFIS) Sistemine Dayalı Hiz Denetim Performansının İncelenmesi. Çukurova Üniversitesi Mühendislik-Mimarlık Fakültesi Dergisi, 31(ÖS2), 33-42. https://doi.org/10.21605/cukurovaummfd.315861

Sönmez, A. Y., Kale, S., Özdemir, R. C., ve Kadak, A. E. (2018). An adaptive neuro-fuzzy inference system (ANFIS) to predict of cadmium $(\mathrm{Cd})$ concentrations in the filyos river, Turkey.
Turkish Journal of Fisheries and Aquatic Sciences, 18(12), 1333-1343. https://doi.org/10.4194/1303-2712-v18_12_01

Söyler, H., ve Kızılkaya, O. (2018). Para Krizlerinin Yapay Zeka Yöntemleri İle Tahmini: Türkiye Örneği. Uluslararası İktisadi ve İdari İncelemeler Dergisi, 16-17. https://doi.org/10.18092/ulikidince.347202

Taylan, D. (2018). Dalgacık-Adaptıf A ğ Temellı Bulanık Çıkarım Sıstemlerı Ile Dalaman Çayı Akımlarının Modellenmesi Üzerine Bir Çalışma. Mühendislik Bilimleri ve Tasarım Dergisi, 6(1), 56-63. https://doi.org/10.21923/jesd.380158

Toylan, H., ve Hüner, E. (2017). Uyarlamalı Sinirsel Bulanık Çıkarım (ANFIS) Tabanlı Güneş Takip Sistemi. Afyon Kocatepe Üniversitesi Fen Ve Mühendislik Bilimleri Dergisi, 17(2), 25202-25546. https://doi.org/10.5578/fmbd.60776

Ünal, A., Aydın, M. M., ve Saplıŏlu, M. (2018). Türk Sürücülerinin Facebook Sosyal Paylaşım Sitesini Trafik Bilgilendirme Ve Radar Yeri Tespiti Amacıyla Kullanımı Üzerine Bir Araştırma. Mühendislik Bilimleri ve Tasarım Dergisi, 6(2), 354-364. https://doi.org/10.21923/jesd.412215

Yang, J. G., Kim, J. K., Kang, U. G., ve Lee, Y. H. (2014). Coronary heart disease optimization system on adaptivenetwork-based fuzzy inference system and linear discriminant analysis (ANFIS-LDA). Personal and Ubiquitous Computing, 18(6), 1351-1362. https://doi.org/10.1007/s00779-013-0737-0

Yılmaz, A., Kaya, U., ve Şaykol, E. (2020). An ANFIS Based Vehicle Sales Forecasting Model Utilizing Feature Clustering and Genetic Algorithms. Havacılık ve Uzay Teknolojileri Dergisi, 13(1), 139-154.

Zadeh, L. A. (1965). Fuzzy sets. Information and Control, 8(3), 338-353. https://doi.org/10.1016/S0019-9958(65)90241-X

Ziasabounchi, N., ve Askerzade, I. (2014). ANFIS Based Classification Model for Heart Disease Prediction. International Journal of Engineering, 14(02), 7. 